\title{
SYSTEMS ECOLOGY, ENERGY NETWORKS, AND A PATH TO SUSTAINABILITY
}

\author{
BRIAN D. FATH \\ Department of Biological Sciences, Towson University, Towson, MD 21252, USA. \\ Advanced Systems Analysis Program, International Institute for Applied Systems Analysis, Laxenburg, Austria.
}

\begin{abstract}
One of the great advances of the 20th century was the rise of a formal systems science and systems thinking. This progress influenced ecology in ways that provided new insight to the structure and function of ecosystems using tools from thermodynamics, networks, information theory, and more. We have been able to increase our understanding of how ecosystems function in terms of using available energy to create complex structures to move away from thermodynamic equilibrium and how these self-organizing structures adapt to changing situations. Ecological goal functions can measure this orientation of ecosystem growth and development (EGD). This presentation addresses how these metrics attuned for ecosystems have relevant application in socio-economic systems. In particular, energy network science is a new paradigm that draws from thermodynamics, information theory, and network analysis to assess the organization, patterns, and dynamics of diverse systems such as ecosystems, financial systems, and urban metabolism. Our understanding of sustainable systems is informed by knowing how ecological and other far-from-thermodynamic equilibrium systems create, maintain, and sustain their functional activities. This approach builds from the seminal efforts of systems thinkers such as Gregory Bateson, Buzz Holling, Jane Jacobs, Sven Jørgensen, Donella Meadows, Jacob Moreno, Bernard Patten, Joseph Tainter, Robert Ulanowicz, and Ilya Prigogine.
\end{abstract}

Keywords: Autocatalysis, Ecological goal functions, Network analysis, Succession, Sustainability, Systems ecology, Thermodynamics.

\section{INTRODUCTION - A THERMODYNAMIC BASIS}

Energy is the ability to do work, making it the primary resource driving all form and function in the universe. Physicists deal with this question along the hierarchies from quantum to cosmic scales. The contributions of Ilya Prigogine and others delve into the complexities that arise from self-organizing processes by systems that are open, receiving and dissipating energy. In essence, these systems reside in energy gradients and use the inflow to create and maintain organized structures through their own processes. These structures become gradients at another scale for other systems.

The great systems scientist Weaver [1] once classified systems into three categories: (1) organized simplicity, (2) disorganized complexity, and (3) organized complexity (Fig. 1). The first category is the realm of classical physics. Newton's laws provide predictive capabilities for the interactions of a few simple particles: billiard balls colliding on a table, locomotives moving across a landscape, planets in motion, etc. This understanding and breakthrough led to great advances in the practice and confidence of science. It turned out that the next major advance regarding our three categories was with disorganized complexity. In the case when there are many particles (molar numbers), the laws of Newton apply, but the large numbers made this approach intractable. The rise of statistical mechanics, notably the work of Ludwig von Boltzmann provided a method to measure macroscopic tendencies of these innumerable moving parts. What became relevant was the average velocity or average density, which led to further breakthroughs in thermodynamics. The recent rise in agent based modelling has attempted to use simple rules of many interacting, heterogeneous particles as a way of combining the two extremes of our continuum, but does not necessarily address the creative 


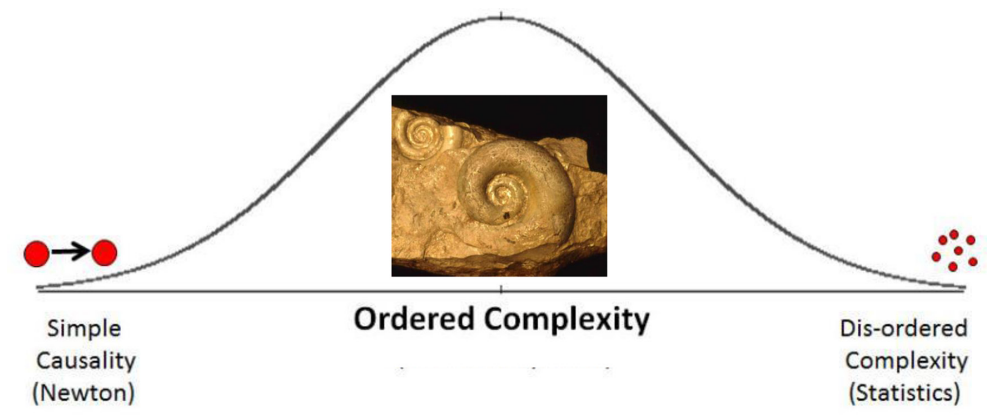

Figure 1: Three categories of systems for scientific exploration according to Weaver [1].

novelty that emerges from organized complexity. Weaver remarked that the next great age of science will progress in the area of systems that exhibit organized complexity. The challenge of organized complexity was undertaken with vigor in the 20th century by many scientists and systems thinkers but is still unfolding and developing toward a rigorous understanding.

Within the ecological literature a sub-field emerged using the ecosystem as the object of study - the complex, self-organized, system [2]. The question ecologists posed was: How to measure the complexity of an ecosystem. Traditional measures such as counts of species or functional roles (niches) were inadequate. For example, number of individuals or number of species was a crude approximation of the system complexity because the dimensions of the data did not match the complexity of the problem. Better success was had in applying thermodynamic principles to measure the level of complexity. These efforts resulted in a plethora of bold proclamations that a 4th Law of Thermodynamics has been found which references evolution or ecosystem development ${ }^{1}$. For example, these include Onsager's reciprocal relations [3], Jørgensen's maximization of work energy capacity [4], HT Odum's maximum power principle [5], and Prigogine's dissipative structures [6]. I am not ready to proclaim that one of them holds that lofty position but do suspect that the fourth law, when discovered, tested, and agreed upon, will deal specifically with the issue of far-from equilibrium complexity and how systems achieve it and how we measure it. This is an open and critical area for future research. Here, my goal is to explore these multiple avenues and look for commonalities and patterns among them. In particular, how they measure complexity in terms of the developmental trends exhibited by ecological succession.

Succession theory [7] tells us that ecosystems, when left to their own uninterrupted devices, will follow a predictable pattern of development that moves the system from simple to more complex structures. Thermodynamically, what is occurring during this time is the increasing capture of energy flows, incorporation of these flows into stored structures and overall greater complexity and energy demands to maintain it. Therefore, a bioenergetics model of succession proposed by Odum [8] shows that net energy available for growth is maximum at some intermediate stage. During the early stages, there is insufficient structure to capture much energy; and, at later stages, the greater amount of energy being captured is utilized by the system for maintenance. This makes it clear that what matters is not the absolute amount of input and output, but rather the difference. A simple input-output model formulation applied to any conserved quantity (energy or matter) can demonstrate this. The steady state situation arises when input and output are equal and, of course, can occur at

${ }^{1}$ For example, see www.humanthermodynamics.com/4th-Law-Variations.html 


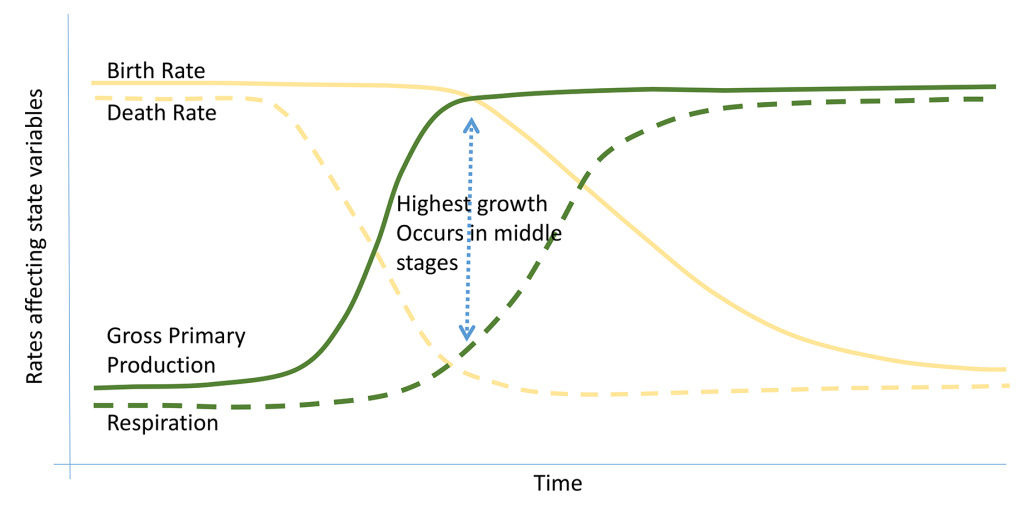

Figure 2: Ecological succession (green lines) and the human population demographic transition (yellow lines) plotted together showing the pattern of growth occurs at the stage of greatest inflow-outflow disparity.

either high or low levels of equal input and output. Although it should be obvious that growth (or degrowth) occurs only when there is a difference, basic systems concepts of flow, stock and accumulation are not readily part of conventional understanding [9, 10]. My own experience with students is similar in that their natural inclination is to focus on absolute inflows and outflows and not the differential. They believe growth must occur when input is high. A case in point, they have a very difficult time rationalizing that human population (the stock), for example, increased not through an increase in birth rate but rather a decrease in death rates (the flow). With the bioenergetics of succession, in the early stages the ecosystem experiences low input but even lower output thus having some available for growth. Through positive feedbacks this moves the system from simple configurations to more complex ones until the later stages have high energy throughflow (high input and output) and high energy storage. However, at this stage there is a low capacity for growth due to the high overhead (output) costs. The demographic transition is sort of a mirror image to succession in which rates go from high-high to low-low in one and low-low to high-high in the other (Fig. 2). In both, the growth occurs in the middle period with the greatest differential.

Ecosystems naturally go through this transition from early stage to late stage in which growth follows a logistic type pattern, in terms of their basic energetics. The question still remains how does the complexity change over time during these stages? And, how can one measure this complexity? Complicating factors further is the realization that systems do not maintain this high level of complexity indefinitely but are also vulnerable to some perturbations that lead to collapse. The standard logistic model has been extended to include the collapse and reorganization in the now ever-present adaptive cycle [11]. This figure shows system connectivity on the $\mathrm{x}$-axis and a measure of complexity on the $\mathrm{y}$-axis. A modified form [12] explicitly recognizes the trial-and-error upward progress followed by rapid, monotonic decay following the perturbation leading to collapse (Fig. 3).

\section{MEASURING COMPLEXITY IN ECOSYSTEMS}

In systems ecology, there has been a concerted effort by a small number of researchers to be able to track and measure the complexity of ecological systems. In other words, an attempt to answer the question what is on the y-axis of Holling's adaptive cycle. As stated above, 


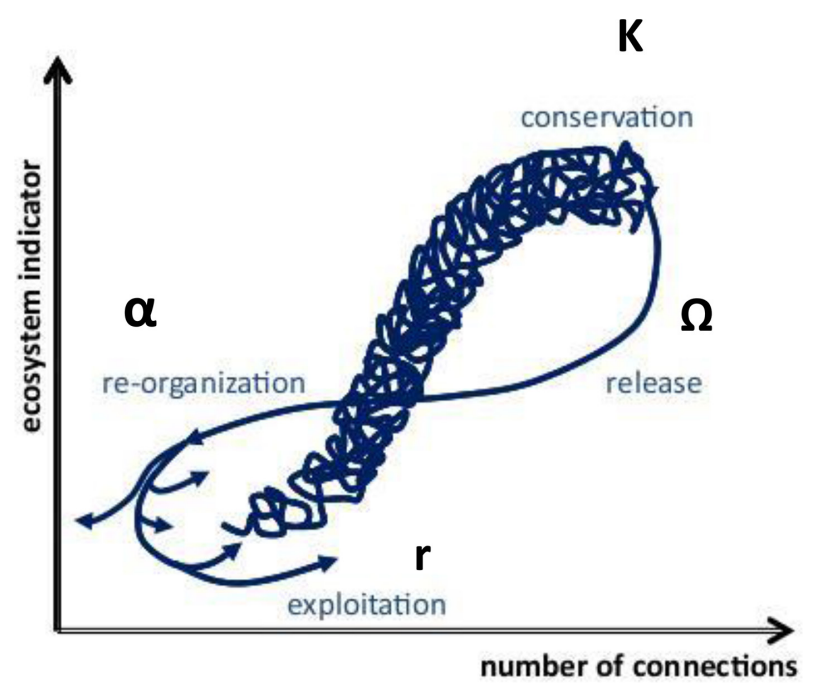

Figure 3: Complex adaptive cycle developed by Holling (1986) showing the four stages of system dynamics from growth $\rightarrow$ equilibrium $\rightarrow$ collapse $\rightarrow$ reorganization. This figure has been modified according to Burkhard et al. (2011).

structural metrics such as diversity or abundance appear too simple, and better success would be had with functional characteristics, namely those that incorporate thermodynamic aspects. In this manner, Prigogine was already paving the way, in that his research into the (self)-organization of far-from-equilibrium systems is what inspired many systems ecologists. Successful measures of ecological complexity include structural AND functional aspects, or function embedded in (network) structure. An unwritten consensus was reached, borrowing from physics, that a good measure of complexity should have both an extensive and an intensive aspect to it. Just as we measure energy as volume (extensive) times pressure (intensive) or entropy (extensive) times temperature (intensive), our measure of ecological complexity should include the amount or quantity and characteristic or quality of the thing being measured. Three different approaches, in particular, are worth noting here (Table 1).

The first metric in Table 1 by Jørgensen and Meijer [13] is termed eco-exergy and is based on the concentration of biomass of a species (extensive) weighted by the informational complexity of the species (intensive). Specifically, the information in this approach is measured as genetic complexity such that there is information in the order of nucleotides within the DNA. Species with a longer alignment of nucleotides in its genome are given a correspondingly larger weighting factor ( $\beta$ ). A second method, developed by Odum [14] uses the species biomass as the extensive variable and weights it by a species-specific transformity, which is a measure of how much solar energy is needed to generate biomass of that species. For example, since it is impossible to have a lion without prey and the prey without forage, the lion indirectly consumes an amount of forage, which in turn had captured solar radiation. This gives a path dependent metric in terms of the total solar energy embedded in the ecosystem, and has been called emergy (for embodied energy). A third approach developed by Ulanowicz [15] uses the network as the scale of study rather than the species. In this case, the network is comprised of energy flows within entire food webs. The extensive variable is the total energy flow through the entire network and the intensive variable is the information within 
Table 1: Various methods to measure 'complexity' in ecological systems. In the formulas: (1) $\beta$ is the weighting factor based on the genetic complexity and $c$ is the concentration of biomass; (2) $E$ is the energy of biomass and $\tau$ is path-dependent 'transformity' converting solar energy into the species biomass; (3) Tij is the total throughflow in the network and second term is 'Boltzmann' information captured in the flow network, where $T$.. is sum of total flow through the network and $T i$ And $T j$ are the flows through $i$ and $j$, respectively.

\begin{tabular}{ll}
\hline Systems ecological approach and developer & $\begin{array}{l}\text { Formula combining extensive (1st term) } \\
\text { and intensive (2nd term) aspects }\end{array}$ \\
\hline
\end{tabular}

(1) Eco-Exergy (SE Jørgensen):

$$
\begin{gathered}
\sum c_{i} \beta_{i} \\
\sum \tau_{i} E_{i} \\
\sum \sum T_{i j} \log \left(\frac{T_{i j} T_{T}}{T_{i, T_{j}}}\right)
\end{gathered}
$$$$
\text { (2) Emergy (HT Odum): }
$$

(3) Ascendency (RE Ulanowicz):

the network flow structure. In other words, information is gained when there is a reduction of uncertainty such that the network constrains or articulates flow. The lower the redundancy, the greater information there is about the system.

\section{ECOLOGICAL GOAL FUNCTIONS}

When considering these measures of ecological complexity, the conversation leads to the question of whether or not they are not just measures of the state of the system but also extremal functions that can be seen as weak (tracking) or strong (driving) the change that is observed in ecosystem growth and development (EGD). These extremal functions have been called orientors or, when used in ecological models, goal functions [16]. A number of ecological goal functions, including the ones above, such as increasing the energy cycling [17], storage [13], dissipation [18], residence time [19], degree of mutualistic relations [20], and minimizing specific dissipation (dissipation per unit of biomass $-[3,6]$ ) have been proposed. Again, here we look to Prigogine as a prescient thinker in this area as his work in dissipative structures led the way to these approaches. Some scholars have promoted the idea that degrading the energy gradient IS the purpose for the structure and therefore the evolution toward more complex structures is actually a trend toward greater dissipative ability. Others have focused on the organization of the structure and its increased complexification as the primary motive trend. The critical duality is that of aggradation and degradation, construction and dissipation. The insight that far from equilibrium physics brings us is that we are working with systems that are obligate open, linked to a continued and sustained flow of energy: these systems reside in an energy gradient. This provides two views of their behavior in the gradient. The first is that they utilize the gradient for their own functions. They use the energy in a way that minimizes the rate of internal entropy generation, while increasing the overall entropy of the system + environment amalgam. This lowers the quality of that available energy gradient: exergy is used up. However, in the process of degrading that energy gradient they create new structures with new gradients. These are the dissipative structures which 
Prigogine spoke of. The spotlight has been shined on both degradation and aggradation processes at varying times as preeminent, but the reality is they are obverse and reverse as one coupled action. As my colleague, Robert Ulanowicz, once remarked (paraphrased), 'While it is true that every time work is done energy gradients must be degraded, it is also true that you cannot degrade an energy gradient without doing some work on the environment' (personal communication). What work is done is key.

Ecosystems have evolved to squeeze as much work out as possible by coupling energy charging and discharging processes together. The network structure provides ample opportunity for material and energy cycles [21]. In this manner, it is also possible to partition energy into aggradation (that builds gradients) or degradation (that dissipates the energy). Imagine one liter of gasoline. The useful energy is stored in the chemical bonds of complex carbon molecules. These bonds themselves came from linked cascades starting with solar radiation forming ATP used to convert carbon dioxide and water into the more complex macromolecule. When the carbon molecule is exposed to high temperature and pressure that energy is released. In one setting, the gasoline is burned in an open pit on a warm, summer day. The local temperature increases marginally from the release of the stored chemical energy, but no meaningful work is done. In another setting, the open pit is overlaid with a grill. While the gasoline energy is dissipated, food placed strategically in the grill receives the heat making it consumable by humans. The exo-somatic energy of the gasoline helps aid in human digestion, which has reverberating consequences of the original chemical energy bonds. In yet another setting, the open pit is fitted with a steam turbine; the energy released from the gasoline heats water to steam and generates electricity. The new voltage gradient can do further work when it is run across a circuit. Each additional step that useful work is done extends the time until total dissipation of the original gradient. The ultimate fate of the energy gradient is the same. A ground will be reached but the pertinent question is how many steps it can accomplish along the way? Each additional coupling to another process at another scale retains it in the system longer, increasing its overall usefulness and purpose (Fig. 4). This concept, applied to ecosystems, was summed eloquently by systems thinker Jane Jacobs as follows:

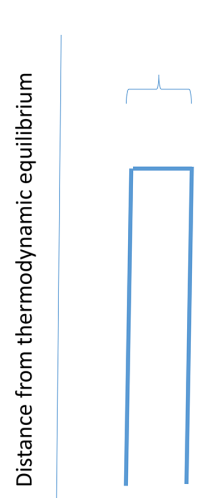

a)

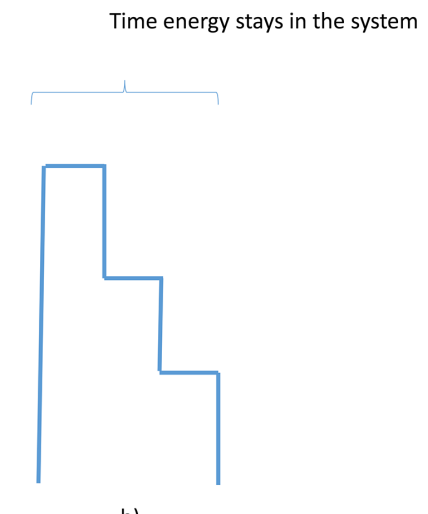

b)

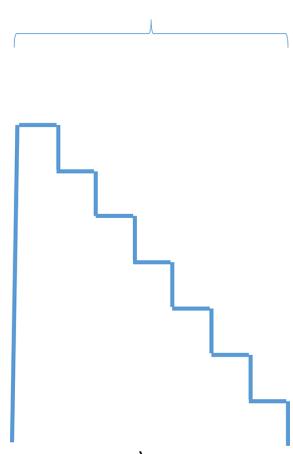

c)

Figure 4: Visualization of an energy pulse that is degraded at different rates depending on the number of intermediate reactions that are coupled to the gradient utilization: a) no coupling, b) moderate coupling, c) extensive coupling. 
"In the forest, energy flow is anything but swift and simple, because the diverse and roundabout ways that the system's web of teeming, interdependent organisms uses energy. Once sunlight is captured in the conduit, it's not only converted but repeatedly reconverted, combined and recombined, cycled and recycled as energy/matter is passed around from organism to organism. Energy flow through an intricate conduit of this kind is dilatory and digressive. It leaves behind, in complex webs of life, ample evidence of its passage" [22, p. 46].

These ecological goal functions, we have shown, are shedding light on different aspects of the same process. The primary ones employed in ecology are complementary to each other, not contradictory. One does not need to be wrong for another to be right. Let me explain in some detail. Our 2001 paper, published in the Journal of Theoretical Biology, looked at 10 different ecological goal functions [23]. We represented each goal function using appropriate network notation and were able to reveal similar and in some cases reinforcing features (Table 2). The two goal functions that were perhaps hardest to reconcile were increasing degradation and decreasing specific dissipation because they appeared in direct opposition. How can total degradation be increasing if degradation per biomass is decreasing? However, upon further investigation, minimizing specific dissipation does not imply that degradation stops. Quite the contrary, we know that it must continue to support the activities of an open system. Referring to the statements above, the important question is what is done with the dissipative flows (respiration) and how much structure (biomass) is created. In other words, the ratio (R/B) can increase simultaneously with an increase in $\mathrm{R}$ as long as $\mathrm{B}$ increases even faster. In the end, we showed the complementarity of all goal functions considered, and identified three as summative: (1) increasing energy acquisition, (2) increasing retention time (i.e. biomass), and (3) increasing cycling. These results engendered the quip: Ecosystems get as much as they can $(\max 1)$, hold on to it for as long as they can $(\max 2)$, and if they must let it go, then try to get it back $(\max 3)$.

Table 2: Ecological goal functions, including the network formulation, showing the similarities in the key goals: increasing energy acquisition, increasing cycling, and increasing retention time (i.e. biomass). See Fath et al. [23] for complete description of the notation.

\begin{tabular}{|c|c|c|c|}
\hline $\begin{array}{l}\text { Goal } \\
\text { Function }\end{array}$ & $\begin{array}{l}\text { Ecological } \\
\text { Representation }\end{array}$ & $\begin{array}{l}\text { Network } \\
\text { Parameter }\end{array}$ & $\begin{array}{l}\text { Network Analysis } \\
\text { Formulation }\end{array}$ \\
\hline $\begin{array}{l}\text { 1. maximize power } \\
\text { (throughflow) }\end{array}$ & $\max (\mathrm{TST})$ & $\mathrm{TST}=\mathrm{f}^{(1)}+\mathrm{f}^{(2)}$ & $\mathrm{TST}=\sum \sum\left(\mathrm{n}_{\mathrm{ij}}\right) \mathrm{z}_{\mathrm{j}}$ \\
\hline $\begin{array}{l}\text { 2. maximize exergy } \\
\text { storage }\end{array}$ & $\max (\mathrm{TSS})$ & $\mathrm{TSS}=\mathrm{x}^{(1)}+\mathrm{x}^{(2)}$ & $\mathrm{TSS}=\sum \sum \tau_{\mathrm{i}}\left(\mathrm{n}_{\mathrm{ij}}\right) \mathrm{z}_{\mathrm{j}}$ \\
\hline $\begin{array}{l}\text { 3. maximize dissipa- } \\
\text { tion }\end{array}$ & $\max (\mathrm{TSE})$ & $\mathrm{TSE}=\mathrm{f}^{(3)}$ & $\mathrm{TSE}=\sum \sum\left(\mathrm{n}_{\mathrm{ij}} / \mathrm{n}_{\mathrm{ii}}\right) \mathrm{z}_{\mathrm{j}}$ \\
\hline $\begin{array}{l}\text { 4. minimize specific } \\
\text { dissipation }\end{array}$ & $\min (\mathrm{TSE} / \mathrm{TSS})$ & $\begin{array}{l}\text { TSE/TSS }=\mathrm{f}^{(3) /} \\
\left(\mathrm{x}^{(1)}+\mathrm{x}^{(2)}\right)\end{array}$ & $\begin{array}{l}\text { TSE/TSS }=\sum \sum\left(\left(\mathrm{n}_{\mathrm{ij}} / \mathrm{n}_{\mathrm{ii}}\right) \mathrm{z}_{\mathrm{j}}\right) / \mathrm{x}_{\mathrm{ij}} \\
=\sum \sum 1 /\left(\tau_{\mathrm{i}} \mathrm{n}_{\mathrm{ij}}\right)\end{array}$ \\
\hline $\begin{array}{l}\text { 5. maximize resi- } \\
\text { dence time }\end{array}$ & $\max (\mathrm{TSRT})$ & $\mathrm{TSRT}=\tau$ & $\begin{array}{l}\text { TSRT }=\sum \sum \mathrm{x}_{\mathrm{i}} /\left(\mathrm{n}_{\mathrm{ij}}\right) \mathrm{z}_{\mathrm{j}} \\
=\sum \sum \tau_{\mathrm{i}}\end{array}$ \\
\hline 6. maximize cycling & $\max (\mathrm{TSC})$ & $\mathrm{TSC}=\mathrm{f}^{(2)}$ & $\mathrm{TSC}=\sum \sum\left(\mathrm{n}_{\mathrm{ij}} / \mathrm{n}_{\mathrm{ii}}\right)\left(\mathrm{n}_{\mathrm{ii}}-1\right) \mathrm{z}_{\mathrm{j}}$ \\
\hline
\end{tabular}


A second point of reconciliation of these goal functions was further developed in a subsequent study in which we looked at the performance of these orientors during different stages of EGD [24]. Along those lines, it is first necessary to distinguish between growth and development. Again, a useful distinction relies on extensive and intensive concepts: growth is a change in quantity and development is a change in quality. As ecosystems go through natural progression of succession, an orderly pattern of growth and development, there are stages in which the quantitative features dominate and others in which the qualitative features do. It is not a strict relay model that one must be complete before the other takes off; there is overlap and also hierarchical diversity such that all processes are occurring simultaneously at varying scales. The model of ecological succession describes this growth and development from an area that is without an ecological community to one that flourishes within it limits given the climatic (e.g. temperature and precipitation) constraints of each biome.

We distinguish four stages of EGD (Fig. 5). The first (referred to as zeroth) EGD stage is boundary growth, which simply means how much energy the system is able to capture across its boundary. Obviously, an increase in input can result in an increase of both throughflow and storage. The second EGD stage, also growth dominated, is biomass growth. This is the stage in which the energy flow is converted to additional biomass storage, greater plant and animal material, and represents a true measurably quantitative increase. As the ecosystem fills with biomass, the next stage represents the network development, an increase in the diversity (differentiation of nodes) and connectivity. A richly connected system is able to retain and utilize the energy inflow more effectively and extract out more structure and organization for the same amount of energy flow - see importance of energy cycling above. The fourth EGD stage
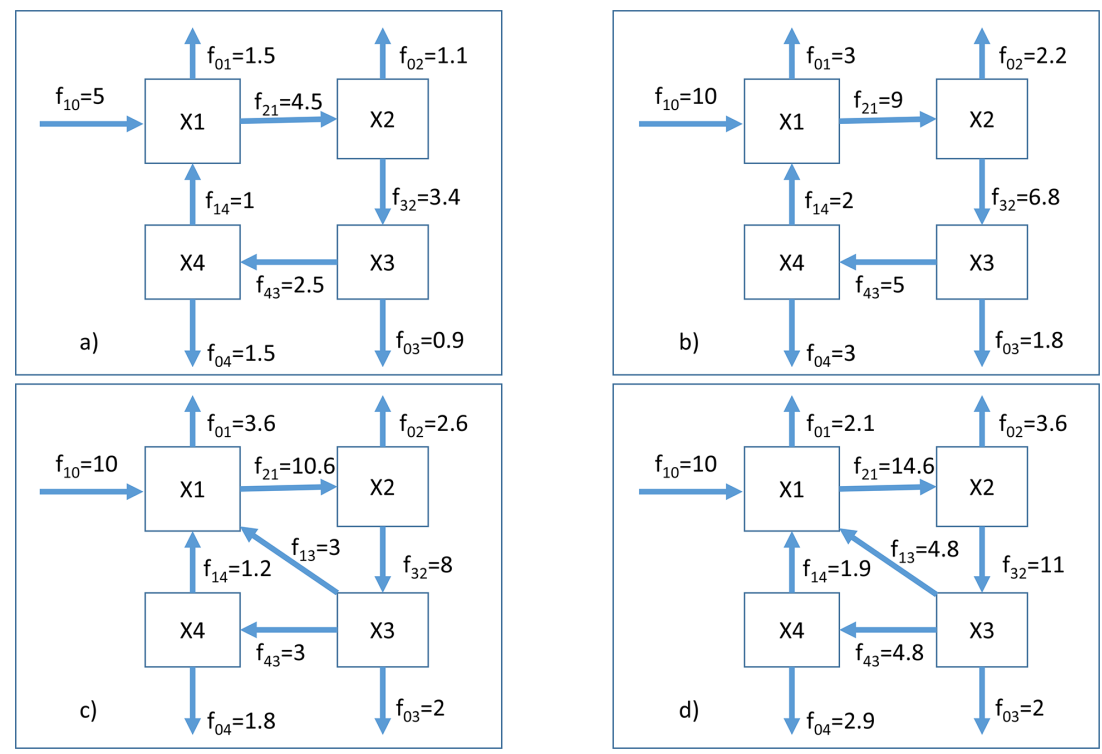

Figure 5: Steady-state model of a four-compartment ecosystem: (a) baseline model. (b) Energy input is doubled (EGD 0), (c) network development (EGD 2), (d) Information development (EGD 3) - respiration for compartments 1 and 3 is reduced from 25 to $12.5 \%$. 
Table 3: Tracking the ecological goal function during different stages of ecosystem growth and development [24].

\begin{tabular}{lllll}
\hline $\begin{array}{l}\text { Goal function } \\
\text { (hypothesized direction) }\end{array}$ & $\begin{array}{l}\text { Boundary } \\
\text { EGD }\end{array}$ & $\begin{array}{l}\text { Structural } \\
\text { EGD }\end{array}$ & $\begin{array}{l}\text { Network } \\
\text { EGD }\end{array}$ & $\begin{array}{l}\text { Information } \\
\text { EGD }\end{array}$ \\
\hline 1. Energy throughflow $(\uparrow)$ & $\uparrow$ & $\uparrow$ & $\uparrow$ & $\uparrow$ \\
2. Exergy storage $(\uparrow)$ & $\uparrow$ & $\uparrow$ & $\uparrow$ & $\uparrow$ \\
$\begin{array}{l}\text { 3. Energy dissipation (exergy } \\
\text { degradation) }(\uparrow)\end{array}$ & $\uparrow$ & $\uparrow$ & $\leftrightarrow$ & $\leftrightarrow$ \\
4. Specific entropy $(\downarrow)$ & $\leftrightarrow$ & $\leftrightarrow$ & $\downarrow$ & $\downarrow$ \\
5. Retention Time $(\uparrow)$ & $\leftrightarrow$ & $\leftrightarrow$ & $\uparrow$ & $\uparrow$ \\
\hline
\end{tabular}

captures information development. This represents the changes that take place within the storage compartments to increase efficiencies and processes through biochemical or even genetic evolution. This is the classic case of doing more for less due to improved utilization, something that is well documented in the course of evolution. In this follow-up study, we investigated the various ecological goal functions in terms of these four growth and development stages and found that, again while all goal functions are compatible, certain goal functions are more 'active' at different stages. Table 3 shows the main results that throughflow and storage are increasing during all stages. Increasing dissipation occurs only during the early stage, while decreasing specific entropy and increasing retention time occur only during later stages.

\section{EXTENSION TO SOCIO-ECOLOGICAL SYSTEMS: URBAN METABOLISM AND REGENERATIVE ECONOMICS}

One of the other great advances we have seen is the understanding that systems dynamics and organization are universal for ALL complex adaptive systems. So the properties that we identify in ecological systems have currency and relevance in socio-economic systems as well. Considering the pressing need for managing ourselves and our resources in a more sustainable way, it is critical that we look to and learn from other systems. We believe that ecological systems, having evolved over many eons, demonstrate the kind of organization and patterns indicative of sustainable systems. We use them not only to look at specific 'engineering technologies', sensu biomimicry, but also as design templates for configuring whole systems that function sustainably.

The added layer of hierarchy that human society brings to bear provides social constraints that allows for even greater levels of integration and complexity. Odum interpreted the rise of society in terms of energetics in his classic work Environment, Power, and Society [25]. Pirsig, the author who is best known for his work Zen and the Art of Motorcycle Maintenance [26], laid out a very insightful hierarchy in his second novel, Lila [27]. He proposed a metaphysics of 'quality' progressing from inanimate to biological to social to intellectual to dynamic (Fig. 6). The idea being that each level should give way to the higher level. For example, social structures arise to constrain and control biological impulses, such as laws against killing and taking; laws that clearly do not exist strictly in the biological realm. Again, note that HT Odum would likely say this is not out of superiority of the higher levels, but because the energetics of the system work better with these constraints - the energy we save 

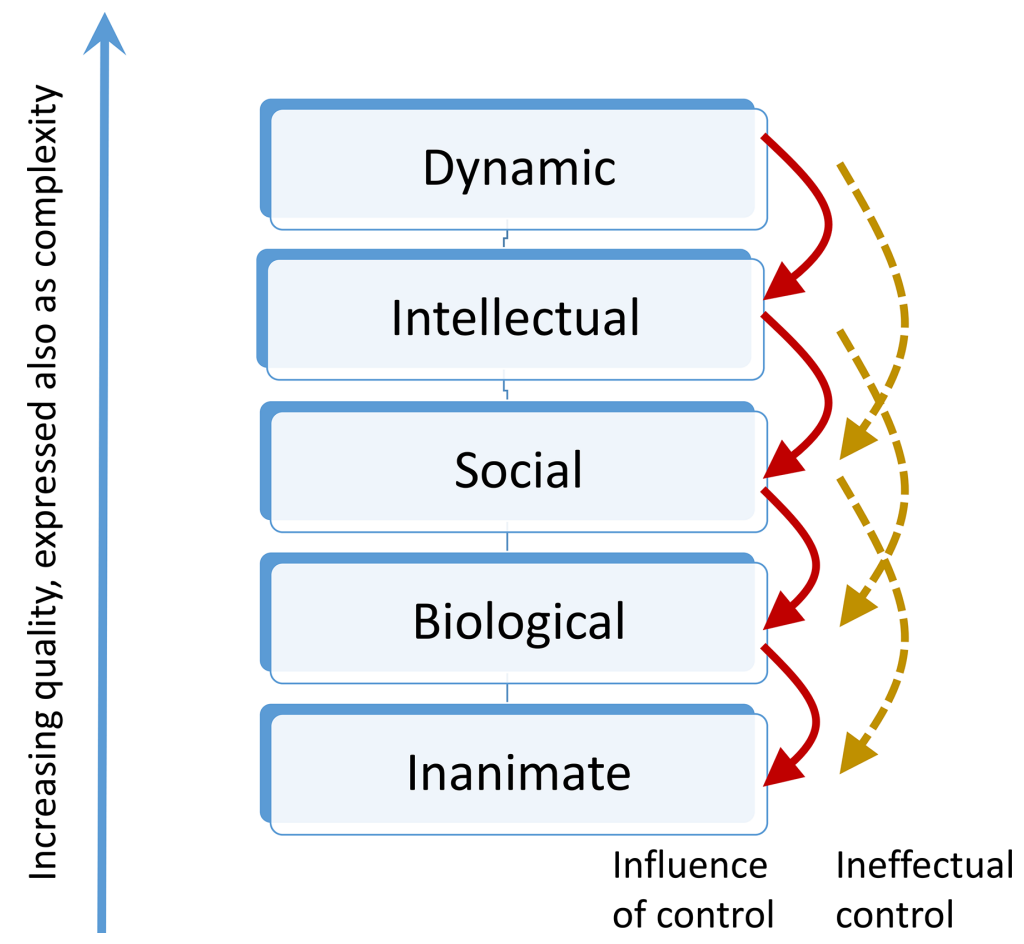

Figure 6: Pirsig's [23] hierarchy for quality and showing controlling factors occur only one level down.

by not having to continually defend and deflect is invested in other complexity building endeavors. Social systems have 'learned' and codified these constraints into laws and customs. Pirsig [27] referred to something as immoral when a lower order process interferes with a higher one, such as biological impulses disrupting social organizations, or social norms banning intellectual works. Interestingly, he posited that the constraints can only be effective one level down. In other words, social norms may effectively prohibit biological impulses, but intellectual arguments are ineffective to quell the same biological impulses. What is most relevant here, is the identification of a hierarchy of value and control, which shows how it is possible that levels of complexification continue beyond merely the biological for improved utilization of the biophysical gradients and resources. Social systems arise not just to put checks on biological urges as vice, but because they help raise the overall level of complexity of the system by further channeling and managing the energy flows. Social systems, as a result, are more complex because they add additional layers of constraint which allows for further development away from thermodynamic equilibrium.

Urban systems utilize energy and matter flows to maintain high levels of complexity, organization, and functionality. In this sense they can be investigated as metabolic, far-from-equilibrium systems and compared to the functioning of living, ecological systems. These flow networks that arise give insight into the sustainability of the urban system. In other words, if the organization is such that in the process of dissipating the metabolic flows, additional gradients are constructed reinforcing the overall urban function, then it has the features of being sustainable. The application of reliable inputs supporting internal 
autocatalytic processes producing healthy outputs to urban areas creates economies that are regenerative and sustainable. There are many interesting studies of urban metabolism [28, 29], however, those specifics are not addressed here. Rather, in the last section I turn to the general features of sustainable systems.

\section{SUSTAINABILITY}

Much effort and attention is directed to the question of sustainability in research and application. I find it useful to distinguish between normative human aspirations and objective system traits that can and do induce sustained functionality. For example, the famous Brundtland Commission (1986) proposed a definition of Sustainable Development that is agreeable and meaningful as a human goal. It states succinctly, that Sustainable Development 'meets the needs of the present generation without compromising the needs of future generations.' As stated before [30], there are three key features of this instrumentation. First, as a statement of a policy goal it is hard to argue with. No one in practice is against these aims. Second, it is intentionally and unabashedly an anthropocentric concept: it is first and foremost about human needs. Third, building off the last point, the word 'needs' does a lot of heavy lifting because it is innocuous and vague. By keeping this undefined, we are more readily eager to join this cause. Usually, in terms of implementation, sustainable development is framed in terms of three dimensions: ecological, economic, and social. The United Nations recently (September, 2015) adopted 17 Sustainable development Goals and they range from 'No poverty' to 'Affordable and clean energy' and 'Climate action' to name a few. This is where the distinction between sustainable development and sustainability is useful. Precisely, sustainable development should be left as an anthropocentric concept aimed at human well-being, but an understanding of maintaining the function of complex adaptive systems should be the focus of a sustainability science. For example, referring to the SDGs above, one could easily imagine that whether a system is truly sustainable or not is completely independent of the economic affordability of energy. Whether the mixed goals implicit in the SDGs ever create an unresolvable loggerhead is an issue for another paper. Rather, I want to conclude this essay with some insights to what a science of sustainability might resemble.

The first principles of sustainability refer back to our basic input-output model. The system in question is open; therefore, it must have reliable inputs and healthy outputs. This means the inputs are steady or pulsing in a predictable way. We think of these as renewable resources, and more basically, the renewable energy source driving ecological systems is solar radiation. Structure that is created off one-time injections of energy will not be sustainable. On the output side, the unwanted byproducts (wastes) generated by the system processes cannot accumulate in a way that interferes with future functioning of the system. In ecosystems this is usually accomplished by linking processes such that the output from one becomes a useful feedstock, or input, to another. Through this constant recycling, material resources do not accumulate in a deleterious fashion. Already, one can see the obvious failings of current human society in terms of sustainability. Our energy sources are largely coming from non-renewable fossil fuels and the large quantities of uncoupled and unprocessed wastes cause impacts ranging from eutrophication, acid deposition, climate change, ocean acidification, and photochemical smog, to name a few. A complicating factor is that the same general processes that create complexity for ecological systems receiving solar radiation are activated for social-economic systems receiving fossil fuels. The non-renewable energy inputs effectively build complex structures that require additional, continued inputs - an unsustainable pattern becomes locked-in. A metaphor for these complex structures was proposed by the 


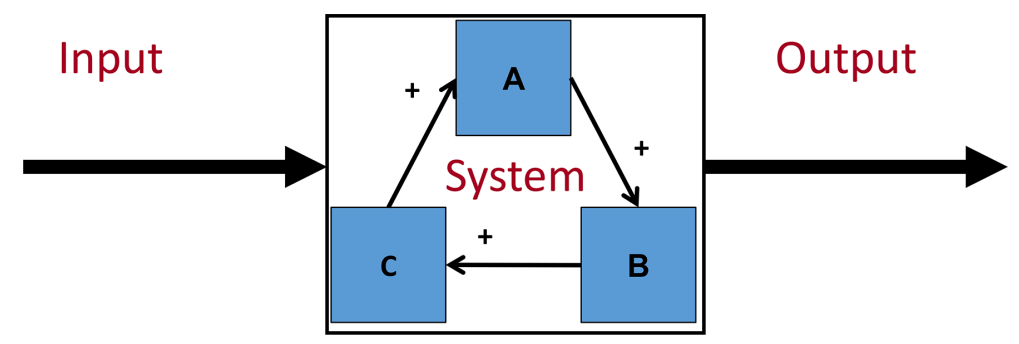

Figure 7: Basic model of a sustainable system that has reliable inputs, which support internal autocatalytic cycles, and produces healthy outputs.

ancient Greek myth of Erysicthon who was cursed for misdeeds such that the more he ate, the hungrier he became. The more energy a complex structure takes in the more it needs to maintain itself. Our current dilemma aside, assuming these basic, necessary requirements of sustainability are met, the next question comes back to what are those internal processes that allow that complexification to occur.

Here, we can turn to properties of complex adaptive systems such as autocatalysis and self-organization. Autocatalysis is a system function in which the action of each participating member facilitates the next. Sustainability is a function of whole systems, not of parts. Therefore, sustainability is predicated on the ability of a system to perform self-reinforcing, positive feedback actions that utilize the available energy gradients but in a way that is coupled to other systems that get purpose and use from those interconnections. Figure 7 shows the combination of input-output constraint driving self-organizing auto-catalytic processes. Admittedly, this is remains a simple, almost trivial, theoretical concept, although we see it occurring over and over, day after day. This lays the foundation for a new line of investigation, which my colleagues and I refer to as energy network science [31]. The aim is to combine network science, thermodynamics, and information theory from an understanding of sustainable ecological systems applied to social-economic systems. The inner workings of sustainable systems using these concepts have only recently been studied.

\section{CONCLUSIONS}

The question of energy gradients is the question of action. Energy is the ability to do work, and all action follows from exploiting energy gradients. The consequences of the 1st and 2nd Laws of Thermodynamics were such that much attention was focused on the impending heat death that would inevitably occur once all energy gradients were dissipated. These fears are overwrought for two reasons, first the time scale at which that will unfold is not generational, ecological, nor even geological, but rather cosmological. So, while it is an interesting question to ponder, these concerns are strictly theoretical and academic. The second piece of the puzzle which is still being worked out is that these gradients are not simply just dissipated and gone, but rather the processes that utilize them are coupled with energy aggrading activities thus delaying the ultimate dissipation to background levels. It is this coupling during dissipation which also gives rise to formation of new structures, dissipative structures, as Prigogine referred to them. These organized structures seemingly arise out of nowhere without external design or intention, thus they are called self-organization systems. The primary question to ask is what is being done during the dissipation of that energy gradient?

All of these fundamental ideas have been studied and researched in the context of ecological systems, but the new approach is to apply them to a plethora of complex adaptive systems 
especially socio-economic systems. Furthermore, the insights gained from ecological systems can be used to guide and inform these socio-economic systems. For instance, we believe that due to co-adaptation and co-evolutionary pressures that ecological systems have survived with a satisfactory balance of the multiplicity of concerns. This is not to say that ecosystems have arrived at an optimal solution because they are dynamic, and having 'arrived' is not an option. These are ongoing processes; they are changing due to both endogenous and exogenous factors and will continue to do so (as long as the primal energy source driving them remains). Nonetheless, the time scale that ecological systems operate gives them 'wisdom' worth mimicking in socio-economic systems. Sustainability is a system feature that occurs when the necessary conditions of reliable inputs and healthy outputs are met and when the internal configurations promote autocatalytic and self-organizing interactions. Again, therefore, an open and ongoing area of research is taking the lessons learned from ecological design and organization and incorporating it into the design of economies, communities, cities, production processes, etc. The rest of the world is taking notice and many of the needed foundations to answers Weaver's question can be found in study of complex, far-from-equilibrium systems and systems ecology.

\section{ACKNOWLEDGEMENT}

All science builds on the previous accomplishments and I am honored to be receiving this award knowing that it arrives due to the foundational results in place as well as the opportunities and collaborators I have had. In particular, I am privileged to have work closely with and been influenced by Bernard C. Patten, Sven Erik Jørgensen, and Robert E. Ulanowicz (all former Prigogine Medalists). I am grateful for discussions and feedback on this draft from Dan Fiscus. Lastly, I want to thank the Wessex Institute and Siena University for supporting the Medal in Prigogine's memory.

\section{REFERENCES}

[1] Weaver, W.A., Quarter Century in the Natural Sciences, The Rockefeller Foundation Annual Report, New York, 1958.

[2] Patten, B.C., Fath, B.D. \& Choi, J.S., Complex adaptive hierarchical systems-background. In: Understanding and Solving Environmental Problems in the 21st Century, eds. R. Costanza, S.E. Jorgensen, Elsevier Science Ltd: London, England, pp. 41-94, 2002.

http://dx.doi.org/10.1016/B978-008044111-5/50005-6

[3] Onsager, L., Reciprocal relations in irreversible processes. Physical Review, 38, pp. 2265-2279, 1931. http://dx.doi.org/10.1103/PhysRev.38.2265

[4] Jørgensen, S.E. \& Svirezhev, Y.M., Towards a Thermodynamic Theory for Ecological Systems. Elsevier. 2004.

[5] Odum, H.T. \& Pinkerton, R.C., Time's speed regulator: the optimum efficiency for maximum power output in physical and biological systems. American Scientist, 43, pp. 331-343, 1955.

[6] Prigogine, I., Thermodynamics of Irreversible Processes, John Wiley \& Son: New York, 1955.

[7] Tansley, A.G., The use and abuse of vegetational concepts and terms. Ecology, 16, 284 307, 1935.

http://dx.doi.org/10.2307/1930070

[8] Odum, E.P., The strategy of ecosystem development. Science, 164, pp. 262-270, 1969. http://dx.doi.org/10.1126/science.164.3877.262 
[9] Sterman, J.D., Communicating climate change risks in a skeptical world. Climatic Change, 108, pp. 811-826, 2011. http://dx.doi.org/10.1007/s10584-011-0189-3

[10] Sweeney, L.B. \& Sterman, J.D., Bathtub dynamics: initial results of a systems thinking inventory. System Dynamics Review, 16(4), pp. 249-286, 2000. http://dx.doi.org/10.1002/sdr.198

[11] Holling, C.S., The resilience of terrestrial ecosystems: local surprise and global change. In Sustainable Development of the Biosphere: Interactions Between the World Economy and the Global Environment. eds. W. C. Clarkand \& R. E. Munn, Cambridge University Press: Cambridge, UK, pp. 292-317, 1986.

[12] Burkhard, B., Fath, B.D., \& Müller, F., Adapting the adaptive cycle: hypotheses on the development of ecosystem properties and services. Ecological Modelling 222(16), pp. 2878-2890, 2011.

http://dx.doi.org/10.1016/j.ecolmodel.2011.05.016

[13] Jørgensen, S.E. \& Mejer, H.F., A holistic approach to ecological modelling. Ecological Modelling, 7, pp. 169-189, 1979.

http://dx.doi.org/10.1016/0304-3800(79)90068-1

[14] Odum, H.T., Self-organization, transformity, and information. Science, 242, pp. 1132 1139, 1988. http://dx.doi.org/10.1126/science.242.4882.1132

[15] Ulanowicz, R.E., Growth and Development: Ecosystem Phenomenology, Springer-Verlag: New York, 1986.

[16] Müller, F. \& Leupelt, M. (eds.), Eco Targets, Goal Functions, and Orientors, SpringerVerlag: New York, 1998.

[17] Morowitz, H.J., Energy Flow in Biology: Biological Organization as a Problem in ' hermal Physics, New York: Academic Press, 1968.

[18] Schneider, E.D. \& Kay, J.J., Complexity and thermodynamics: towards a new ecology. Futures, 24, pp. 626-647, 1994.

http://dx.doi.org/10.1016/0016-3287(94)90034-5

[19] Cheslak, E.F. \& Lamarra, V.A., The residence time of energy as a measure of ecological organization. In Energy and Ecological Modelling, eds. W.J. Mitsch, R.W. Bossermann, \& J.M. Klopatek, Amsterdam: Elsevier, pp. 591-600, 1981.

[20] Fath, B.D. \& Patten, B.C., Network orientors: "Utility" as a goal function. In Eco Targets, Goal Functions, and Orientors, eds. F. Müller \& M. Leupelt, Springer-Verlag: New York, pp. 161-176, 1998.

http://dx.doi.org/10.1007/978-3-642-58769-6_10

[21] Patten, B.C., Energy cycling in the ecosystem. Ecological Modelling, 28, pp. 1-71, 1985. http://dx.doi.org/10.1016/0304-3800(85)90013-4

[22] Jacobs, J., The Nature of Economies, Vintage Books: New York, NY, 2000.

[23] Fath, B.D., Patten, B.C. \& Choi, J.S., Complementarity of ecological goal functions. Journal of Theoretical Biology. 208, pp. 493-506, 2001. http://dx.doi.org/10.1006/jtbi.2000.2234

[24] Fath, B., Jørgensen, S.E., Patten, B.C. \& Straškraba, M., Ecosystem growth and development. Biosystems, 77, pp. 213-228, 2004.

http://dx.doi.org/10.1016/j.biosystems.2004.06.001 
[25] Odum, H.T., Environment, Power, and Society, John Wiley and Sons: New York, NY, 1971.

[26] Pirsig, R.M., Zen and the Art of Motorcycle Maintenance: An Inquiry into Values, William Morrow Publisher: New York, NY, p. 418, 1974.

[27] Pirsig, R.M., Lila: An inquiry into Morals, Bantam Books: New York, NY, p. 409, 1991.

[28] Zhang, Y., Zheng, H. \& Fath, B.D., Analysis of the energy metabolism of urban socioeconomic sectors and the associated carbon footprints: Model development and a case study for Beijing. Energy Policy, 73, pp. 540-551, 2014.

http://dx.doi.org/10.1016/j.enpol.2014.04.029

[29] Zhang, Y., Xia, L., Fath, B.D., Yang, Z., Yin, X., Su, M., Liu, G. \& Li, Y., Development of a spatially explicit network model of urban metabolism and analysis of the distribution of ecological relationships: case study of Beijing, China. Journal of Cleaner Production, 112, pp. 4304-4317, 2016.

http://dx.doi.org/10.1016/j.jclepro.2015.06.052

[30] Fath, B.D., Quantifying economic and ecological sustainability. Ocean \& Coastal Management, 108, pp. 13-19, 2015.

http://dx.doi.org/10.1016/j.ocecoaman.2014.06.020

[31] Goerner, S., Fiscus, DA. \& Fath, BD., Using Energy Network Science (ENS) to connect resilience with the larger story of systemic health and development. Emergence: Complexity \& Organization, 17(3), 2015.

\section{BIOGRAPHY}

Briasn D. Fath is Professor in the Department of Biological Sciences at Towson University (Maryland, USA) and Research Scholar within the Advanced Systems Analysis Program at the International Institute for Applied Systems Analysis (Laxenburg, Austria). He teaches courses in ecosystem ecology, environmental biology, networks, and human ecology and sustainability. Prof. Fath has also taught courses on ecological networks and modeling in Portugal, China, Italy, Germany, Denmark, Croatia, France, Russia, and South Africa. He holds visiting faculty appointments at the School of Environment, Beijing Normal University and at the State Key Laboratory of Urban and Regional Ecology, Chinese Academy of Sciences both in Beijing, China. He was a Fulbright Distinguished Chair at Parthenope University of Naples, Italy in spring 2012 and recipient of the Prigogine Medal in 2016.

His research is in the area of systems ecology and network analysis applied to the sustainability and resilience of socio-ecological systems. His interests range from network analysis to ecosystem theory to urban metabolism to systems thinking and environmental philosophy.

Prof. Fath has published more than 150 research papers, reports, and book chapters. He co-authored three books: Flourishing Within the Limits to Growth: Following Nature's Way (2015), Ecological Modelling (4th edition, 2011), and A New Ecology: Systems Perspective (2007). He is also Editor-in-Chief for the journal Ecological Modelling; Editor-in-Chief for Encyclopedia of Ecology (2nd edition, to be published 2018); President of the North American Chapter of the International Society for Ecological Modelling; Chair of the Ecosystem Dynamics Focus Research Group in the Community Surface Modeling Dynamics System; and, member and past Chair of Baltimore County Commission on Environmental Quality. 